\title{
Sonic hedgehog promotes generation and maintenance of human forebrain Olig2 progenitors
}

\author{
J. Alberto Ortega ${ }^{1+}$, Nevena V. Radonjićc ${ }^{1,2+}$ and Nada Zecevic ${ }^{1 *}$ \\ Department of Neuroscience, University of Connecticut Health Center, Farmington, CT, USA \\ 2 Institute of Medical and Clinical Biochemistry, School of Medicine, University of Belgrade, Belgrade, Serbia
}

\section{Edited by:}

Jose M. Garcia-Verdugo, University of Valencia, Spain

\section{Reviewed by:}

Shaoyu Ge, SUNY Stony Brook, USA Jie Zhang, University of Texas Health Science Center at San Antonio, USA

\section{*Correspondence:}

Nada Zecevic, Department of Neuroscience, University of Connecticut Health Center, 263 Farmington Avenue, Farmington, CT 06030, USA

e-mail: nzecevic@neuron.uchc.edu

${ }^{\dagger}$ These authors have contributed equally to this work.
Function of oligodendrocytes (OLs), myelin forming cells in the CNS, is disrupted in demyelinating diseases such as periventricular leukomalacia or multiple sclerosis. It is, thus, important to better understand factors that can affect generation or differentiation of human OLs. In rodents, Sonic hedgehog (Shh) is influencing expression of Olig2, a helix-loop-helix transcription factor required for development of OLs. In humans, Olig2 is present in cortical progenitors at midgestation, however the role of Shh in the specification of human OLs, including Olig2 positive $\left(\mathrm{Olig}^{+}\right)$progenitors, is not fully understood. Here we studied in vitro effects of Shh signaling on proliferation and specification of human cortical Olig2 ${ }^{+}$progenitors at midgestation. First, we established that the spatial pattern of Olig2 expression in the human developing CNS, described on cryosections, was preserved in mixed and enriched radial glia cell (RGC) cultures. Next, we demonstrated that in vitro treatment with Shh induced an increase in the number of Olig2 ${ }^{+}$progenitors. Shh treatment increased the density of early oligodendrocyte progenitors (OPCs) at the expense of RGC, while the number of late OPCs, did not change. However, inhibition of endogenous Shh with cyclopamine did not reduce the density of $\mathrm{Olig}^{+}$cells, implying the presence of an additional Shh-independent mechanism for OLs generation in vitro. These results suggest that the primary role of Shh signaling in the human dorsal oligodendrogenesis is the expansion and specification of multipotent radial glia progenitors into Olig2 ${ }^{+}$early OPCs. These results obtained in vitro are relevant to understand primary myelination during CNS development, as well as remyelination in demyelinating diseases.

Keywords: glia, cortical development, cellular fate, myelination, transcription factors

\section{INTRODUCTION}

The origin and differentiation of oligodendrocytes (OLs) have been extensively studied in animal models, and are especially well documented in rodents, mainly due to advances in genetic mapping of cell lineages (He et al., 2001; Marshall and Goldman, 2002; Fogarty et al., 2005; Kessaris et al., 2006). In the rodent telencephalon, the majority of embryonic OLs are generated in the ventral forebrain (ganglionic eminence, GE), but a subpopulation of OLs is also generated postnatally in the cortical subventricular zone (SVZ) (Levison and Goldman, 1993; Gorski et al., 2002; Kessaris et al., 2006; Richardson et al., 2006; Kessaris et al., 2008). Notably, it has been suggested that only dorsally generated OLs remain in the adult mouse brain (Kessaris et al., 2006). In the human developing brain, OLs differentiation proceeds through similar stages described in rodents (Rivkin et al., 1995; Back et al., 2001; Ulfig et al., 2002; Wilson et al., 2003; Jakovcevski and Zecevic, 2005; Jakovcevski et al., 2009). At midgestation, human oligodendrocyte progenitor cells (OPCs) originate both in the ventral and dorsal telencephalon (Rakic and Zecevic, 2003; Jakovcevski et al., 2009). Cells generated from these two sources could potentially differ in vulnerability or response to environmental factors. This might be clinically important in various diseases, from the ones that present with demyelination, such as multiple sclerosis (MS) or hereditary leukodistrophy, to complex neurological disorders such as Alzheimer's disease and schizophrenia (Goldman et al., 2012).

In rodents, radial glial cells (RGCs) and several intermediate precursor cells, presumably generated from RGCs, give rise to OLs in the developing CNS (Raff et al., 1998; Rao et al., 1998; Fogarty et al., 2005; Casper and Mccarthy, 2006; Kriegstein and AlvarezBuylla, 2009). Along oligodendroglial lineage, cells change their morphologies and expression pattern of OLs- specific proteins. Early OPCs are bipolar migratory cells that express chondroitinsulfate proteoglycan (NG2) and platelet-derived growth factor receptor alpha (PDGFR $\alpha)$. They differentiate into late OPCs which can be labeled with anti-O4 antibody, and finally into premyelinating and myelinating OLs recognized by anti-O1 antibody and antibodies to myelin basic protein (MBP) and proteolipid protein (PLP), respectively; these cells do not proliferate or migrate (Pfeiffer et al., 1993; De Castro and Bribián, 2005; Meijer et al., 2012).

In addition to similar sequential expression of immunohistochemical markers during the progression of OLs lineage in humans, we have reported that in vitro human fetal RGCs can generate OLs and that this process is enhanced by Sonic hedgehog (Shh) (Jakovcevski et al., 2009; Mo and Zecevic, 2009). Shh 
is an essential morphogen critical for normal development of the brain, especially for its ventral patterning (Gritli-Linde et al., 2001; Marti and Bovolenta, 2002; Ruiz I Altaba et al., 2002). Moreover, Shh promotes OPCs specification from both ventral and dorsal sources (Kessaris et al., 2004). This effect of Shh is particularly important after brain injury, since it might contribute to remyelination (Amankulor et al., 2009; Ferent et al., 2013). Shh exerts its function through spatiotemporal interaction with a variety of transcription factors such as Pax6, Dlx2, Nkx2.1, Nkx2.2, Olig1, and Olig2 (Nery et al., 2001; Fuccillo et al., 2006; Xu et al., 2010; Balaskas et al., 2012). A dynamic combination of these transcription factors plays an important role in OLs differentiation (Nery et al., 2001; Nicolay et al., 2007).

Olig 1 and 2 (Oligodendrocyte Lineage Genes) are basic helixloop-helix (bHLH) transcription factors expressed in response to ventrally secreted Shh in rodents. Gain-and-loss-of-function studies confirmed that Olig genes are necessary and sufficient for generation of OLs (Lu et al., 2000; Zhou et al., 2000; TekkiKessaris et al., 2001). Since the human brain is much larger, has a prolonged time of differentiation and myelination, and numerous evolutionary adaptations, the findings on OL lineage cells and Olig genes obtained in animal models cannot be directly extrapolated to the human brain. Olig genes have a great clinical relevance since they might be involved in demyelination/remyelination pathologies in MS patients and in brain lesions (Arnett et al., 2004; Fancy et al., 2004; Meijer et al., 2012). Moreover, Olig2 is selectively up-regulated after brain injury (Buffo et al., 2005), in diffuse gliomas (Ligon et al., 2004), and is linked to schizophrenia and Alzheimer's disease (Georgieva et al., 2006). Furthermore, this transcription factor has an unusual dual role in development; it first promotes expansion of the neural progenitor pool, and later affects specification and differentiation of OL lineage (reviewed in Meijer et al., 2012). Olig2 has been reported by us and others to be more involved in OL specification than Olig1 (Jakovcevski and Zecevic, 2005; Meijer et al., 2012; Mei et al., 2013). This is why in this study we focused on Olig2 progenitors, and on the effect of Shh signaling on their proliferation and differentiation in human fetal telencephalon at midgestation (ages ranging from 14 to 19 gestational weeks, gw).

We demonstrate that Shh signaling promotes Olig2 ${ }^{+}$cell proliferation and influences specification of RGCs into early OPCs $\left(\mathrm{PDGFR} \alpha^{+}\right)$, but its role in further differentiation into late OPCs is still not clear.

\section{MATERIALS AND METHODS HUMAN FETAL BRAIN TISSUE AND CELL CULTURES}

Tissues for cell cultures were dissected from human fetal forebrains ( $n=8$, Table 1 ) ranging in age from 14 to $19 \mathrm{gw}$, obtained from Advanced Bioscience Resources (ABR, Alameda, CA) and StemEx (Diamond Springs, CA) with proper parental consent and the approval of the Ethics Committees. No evidence of disease or abnormalities was observed after ultrasound and neuropathological examination of fetal brains. The stage of development was estimated as gw after conception and ultrasound findings. Brain tissue was collected in oxygenized Hank's balanced salt solution (Invitrogen, Carlsbad, CA) and transported on ice. Tissue from the cerebral cortex and ganglionic eminence
Table 1 | Fetal human brain tissue used in this study.

\begin{tabular}{lllll}
\hline Case & $\begin{array}{l}\text { Gestational } \\
\text { week (gw) }\end{array}$ & Gender & $\begin{array}{l}\text { Direct tissue } \\
\text { application }\end{array}$ & $\begin{array}{l}\text { Cell culture } \\
\text { application }\end{array}$ \\
\hline 1 & 14 & NP & - & ICC, RT-PCR, WB \\
2 & 15 & 9 & IHC & - \\
3 & 16 & $\sigma^{\prime \prime}$ & RT-PCR & - \\
4 & 17 & $\sigma^{\prime \prime}$ & - & ICC, RT-PCR, WB \\
5 & 17 & $\sigma^{\prime}$ & - & RT-PCR \\
6 & 17 & NP & - & ICC \\
7 & 18 & NP & RT-PCR & ICC, RT-PCR \\
8 & 19 & $\sigma^{\prime}$ & - & ICC \\
\hline
\end{tabular}

o, female; o", male; ICC, immunocytochemistry; IHC, immunohistochemistry; NP, not provided; RT-PCR, real-time PCR; WB, western blot.

was dissected out and dissociated mechanically and enzymatically $(0.025 \%$ trypsin-EDTA, Invitrogen, Carlsbad, CA; DNAse I, $2 \mathrm{mg} / \mathrm{ml}$, Sigma, Saint Louis, MO). Cells were seeded in expansion medium: DMEM/F12 Medium (Invitrogen, Carlsbad, CA) supplemented with B27 conditional medium (Invitrogen, Carlsbad, CA), basic fibroblast growth factor (bFGF) $(10 \mathrm{ng} / \mathrm{ml}$, Peprotech, Rocky Hill, NJ), epidermal growth factor (EGF) $(10 \mathrm{ng} / \mathrm{ml}$, Millipore, Billerica, MA) and Penicillin/Streptomycin antibiotics (Invitrogen, Carlsbad, CA) on Poly-D-Lysine (Sigma, Saint Louis, MO) coated flasks. RGC were isolated using MACS immunomagnetic sorting protocol with CD15 microbeads (Miltenyi Biotech, Auburn, CA). To isolate PDGFR $\alpha^{+}$OPCs, cells were first immunolabeled with mouse anti-human CD140a antibody (1:25, BD Pharmingen, San Jose, CA) and then magnetically immunosorted by rat anti-mouse IgG2a+b secondary antibody conjugated with magnetic beads (Miltenyi Biotech, Auburn, CA).

For pharmacological treatments, $2 \times 10^{6}$ and $25 \times 10^{4}$ cells were seeded in Poly-D-lysine coated 6-well and 24-well plates respectively. Cells were cultured for 1-3 days in expansion medium and then treated with Shh $(200 \mathrm{ng} / \mathrm{ml}$, R\&D systems, Minneapolis, MN) and/or cyclopamine (2.5 $\mu \mathrm{M}$, EnzoLife Sciences, NY) in differentiation medium (expansion medium without bFGF and EGF) applied to cells every 3 days for 14 days in vitro (DIV).

Three distinct differentiation media were used to promote OLs generation and maturation from RGC and OPC cultures. Apart from control medium (DMEM/F12, B27), we used OPCs expansion medium to potentiate differentiation of OPCs. This medium contained DMEM/F12, N2 conditional medium (Invitrogen, Carlsbad, CA) and PDGFaa (10 ng/ml, Peprotech, Rocky Hill, NJ). In order to get more mature OLs, we used a OLs differentiation medium and a protocol where cells were cultured first for 2 days in DMEM/F12, N2 and PDGFaa and then for an additional $14 \mathrm{DIV}$ in DMEM/F12, N2, NT3 $(10 \mathrm{ng} / \mathrm{ml}$, Peprotech, Rocky Hill, NJ) and T3 (30 ng/ml, Sigma, Saint Louis, MO) (Dugas et al., 2006).

For immunohistochemistry, an additional 10 specimens were available, ranging in age from $5 \mathrm{gw}$ to newborn. These cases were subject of previous reports (Jakovcevski and Zecevic, 2005; Zecevic et al., 2005; Jakovcevski et al., 2009). 


\section{REAL-TIME PCR}

A Real-time PCR was used to determine the expression of GAPDH (Glyceraldehyde 3-phosphate dehydrogenase), Olig2, and PDGFR $\alpha$. Total RNA was extracted from cells using TRIZOL ${ }^{\circledR}$ reagent (Invitrogen, Carlsbad, CA) according to the manufacturer's instructions. Approximately $1 \mu \mathrm{g}$ of RNA was used in the reverse transcription reaction using M-MuLV reverse transcriptase with random hexamers (Fermentas, Vilnus, Lithuania) according to the manufacturer's instructions. Real-time PCR was performed in a Realplex2 Mastercycler (Eppendorf, Hamburg, Germany) using 96-well reaction plates (Eppendorf, Hamburg, Germany). The reactions were prepared according to the standard protocol for one-step QuantiTect SYBR Green RT-PCR (Applied Biosystems, Cheshire, UK). The sequences $5^{\prime} \rightarrow 3^{\prime}$ of the forward $(\mathrm{F})$ and reverse $(\mathrm{R})$ primers were as follows:

\section{GAPDH:(F)ACCACCATGGAGAAGGC/(R)GGCATGGACTG} TGGTCATGA

Olig2:(F)AGTCATCCTCGTCCAGCACC/(R)TCCATGGCGAT GTTGAGGT

PDGFR $\alpha:(F) A A A T C T A T G T T A G A C T C A G A A G T C /(R)$ AGTAGAATCCACCATCATGCC

The thermal cycle conditions were $95^{\circ} \mathrm{C}$ for $2 \mathrm{~min}$ followed by 40 cycles of $15 \mathrm{~s}$ at $95^{\circ} \mathrm{C}, 15 \mathrm{~s}$ at $55^{\circ} \mathrm{C}$ and $20 \mathrm{~s}$ at $68^{\circ} \mathrm{C}$. All assays were performed in triplicates. Averaged cycle of threshold $(\mathrm{Ct})$ values of GAPDH triplicates were subtracted from $\mathrm{Ct}$ values of target genes to obtain $\Delta \mathrm{Ct}$, and then relative gene expression was determined as $2-\Delta \mathrm{Ct}$. The results were presented relative to the control value, which was arbitrarily set to 1 .

\section{WESTERN BLOT ANALYSIS}

Cells were homogenized in lysis buffer $[50 \mathrm{mM}$ Tris- $\mathrm{HCl} \mathrm{pH}$ 7.4, $150 \mathrm{mM} \mathrm{NaCl}, 1 \% \mathrm{NP}-40,1 \mathrm{mM}$ phenylmethylsulphonyl fluoride, and protease inhibitor cocktail] on ice for $30 \mathrm{~min}$, centrifuged at $14,000 \mathrm{~g}$ for $15 \mathrm{~min}$ at $4^{\circ} \mathrm{C}$, and the supernatants were collected as the cell lysates. Protein extracts obtained from cultures were separated by SDS-PAGE and electro-transferred to a nitrocellulose membrane (Bio-Rad, Hercules, CA). Membranes were blocked and incubated first with primary antibodies antiOlig2 (1:500, Millipore) and anti-GAPDH (1:3000, Millipore) overnight at $4{ }^{\circ} \mathrm{C}$, and then with their corresponding secondary HRP-conjugated antibodies (1:15000, Thermo Fisher Scientific, Temecula, CA). Protein signal was detected using SuperSignal West Pico Chemiluminescent system (Thermo Fisher Scientific, Temecula, CA).

\section{IMMUNOCYTOCHEMISTRY AND IMAGE ANALYSIS}

Cell cultures were fixed with $4 \%$ paraformaldehyde $/ 0.2 \%$ glutaraldehyde, blocked $1 \mathrm{~h}$ in PBS with $0.2 \%$ bovine serum albumin (BSA) and subsequently incubated with primary antibodies diluted in phosphate buffer solution (PBS) with $0.5 \%$ BSA, $5 \%$ normal goat serum (NGS) and $0.5 \%$ Tween $20^{\circledR}$ at $4^{\circ} \mathrm{C}$ overnight. Primary antibodies against the following proteins were used: rabbit anti-brain lipid binding protein (BLBP; 1:1000, Abcam, UK), mouse anti-Ki67 (1:50, Dako, Denmark), mouse anti-MAP2 (1:200, Sigma, Saint Louis, MO), mouse anti-NG2
(1:100, Chemicon), mouse anti-PDGFR $\alpha$ (1:25, Pharmingen, San Diego, CA), rabbit anti-Olig2 (1:500, Millipore), mouse antiO4 (1:50, generous gift from Dr. Bansal), mouse anti-vimentin (1:100, Sigma, Saint Louis, MO). Primary antibodies were followed by the appropriate secondary antibodies conjugated with Alexa488 or Alexa555 fluorophores (1:500, Molecular Probes, Eugene, Oregon) for $1 \mathrm{~h}$ and a short incubation in bisbenzimide (Sigma) for nuclear staining.

Immunohistochemistry on frontally cut cryosections $(15 \mu \mathrm{m})$ of fetal brains was performed as previously described (Jakovcevski and Zecevic, 2005). Tissue sections and cell cultures were visualized with the Axioskop microscope (Zeiss, Germany) using Axiovision software and photographed with a digital camera. Images were assembled in Adobe Photoshop (v. 7.0), with adjustments for contrast, brightness and color balance to obtain optimum visual reproduction of data. Immunolabeled cells from nine predesigned adjacent optical fields were analyzed by Image J software (National Institutes of Health, Bethesda, Maryland). T-test was used to discriminate between the means, with significance levels set at $p<0.05$ and $p<0.01$.

\section{RESULTS AND DISCUSSION}

\section{Olig2+ CELLS IN HUMAN TELENCEPHALON AT MIDGESTATION}

We first assessed distribution of Olig2 immunolabeled cells through increasing developmental stages, from 5-19 gw and in neonatal forebrain (Figure 1A). A considerable difference in the number of Olig2 ${ }^{+}$cells was observed throughout the forebrain, with higher density seen in the ventral telencephalon, in the GE, whereas in the cerebral cortex, Olig2 ${ }^{+}$cells were observed mainly in the subplate layer and in the ventricular/subventricular zone (VZ/SVZ), but not in the cortical plate. Example of Olig2 ${ }^{+}$cells distribution is shown in the 15 gw forebrain (Figure 1B). Realtime PCR analysis from human fetal brain tissues (16 and 18 gw) supported these findings and demonstrated that the levels of Olig2 mRNA were significantly higher in the GE compared to the cortex (CX) (Figure 1C). Taken together, these results are in accord with the finding that during midgestation, human OPCs are more numerous in the GE than in the cortex, suggesting their initial generation in the ventral telencephalon (Rakic and Zecevic, 2003; Jakovcevski and Zecevic, 2005; Jakovcevski et al., 2009). Scattered Olig2 ${ }^{+}$cells observed in the subplate layer probably represent the first cortical OPCs, as both $\mathrm{O}^{+}$and PDGFR $\alpha^{+}$cells have been described in the same region and at the same developmental stages (Rakic and Zecevic, 2003; Jakovcevski et al., 2009). It is possible that the transient subplate layer, which hosts numerous afferent and efferent fibers (McConnell et al., 1989; Kostovic and Rakic, 1990; Jacobs et al., 2007), supports OPCs differentiation (Jakovcevski et al., 2009). As cortical development proceeds, enriched Olig2 expression is observed in the expanded human outer SVZ (Back et al., 2001; Rakic and Zecevic, 2003; Jakovcevski and Zecevic, 2005; Jakovcevski et al., 2009). In rodents, similar expression of Olig2 is reported in the intermediate progenitors of the SVZ and along white matter tracts, such as the corpus callosum, during perinatal development and even in the gray matter where it remains in quiescent progenitors for mature OL turnover (Levison and Goldman, 1993; 

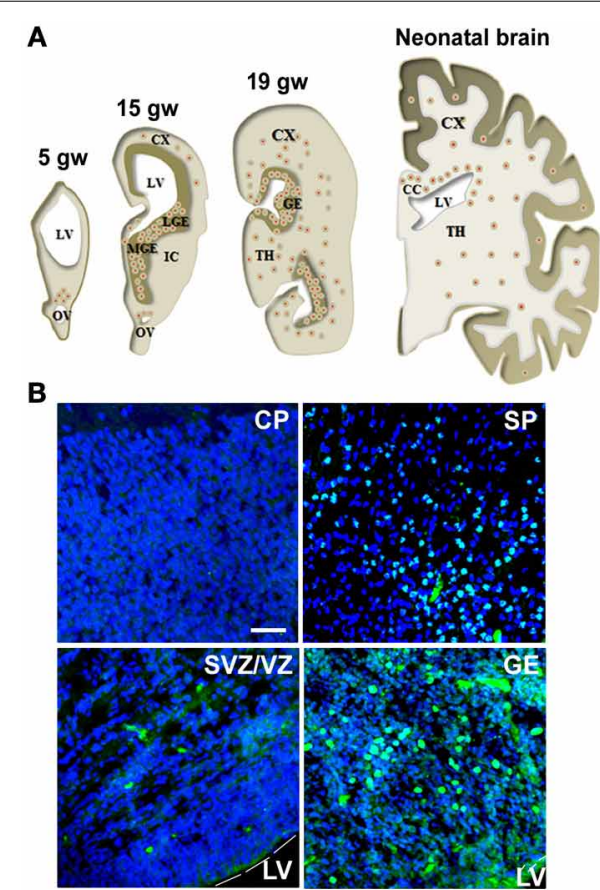

C

Olig2 mRNA levels in
$16-18 g w$ telencephalon

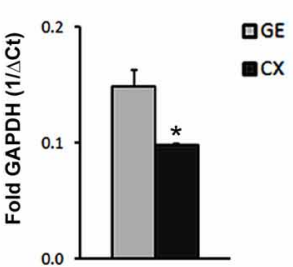

D

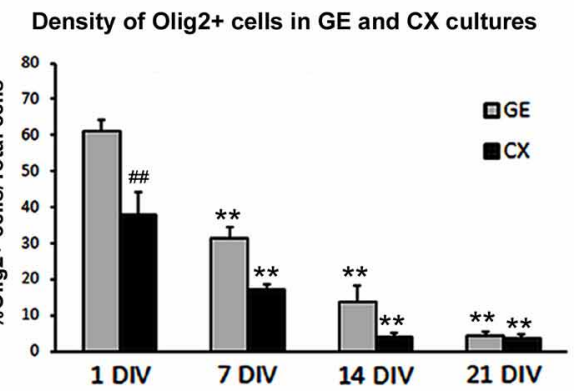

FIGURE 1 | Olig2 expression in the human fetal forebrain. (A)

Schematic representation of the distribution of Olig2 ${ }^{+}$cells (red dots) in frontal sections of the fetal (5-19 gw) and neonatal human

telencephalon. (B) Representative Olig2 (green) immunostaining in $15 \mathrm{gw}$ fetal forebrain. Nuclear staining with bisbenzimide (BB) in blue. (C) RT-PCR levels for mRNA Olig2 in CX and GE in 16-18 gw human brains. Data are presented as mean \pm standard deviation. (D) Percentage of
Olig2 ${ }^{+}$cells in ventral (GE) and cortical (CX) cultures. Data are presented as mean \pm s.e.m. (9 optical fields quantified in each culture) ${ }^{*} p<0.05,{ }^{* *} p<0.01$ vs. control; \#\# $p<0.01-$ GE vs. CX. Scale bar: $20 \mu \mathrm{m}$. CC, Corpus Callosum; CP, Cortical Plate; IC, Internal Capsule; IZ, Intermediate Zone; LGE, Lateral Ganglionic Eminence; LV, Lateral Ventricle; MGE, Medial Ganglionic Eminence; OV, Optical Vesicle; SP, Subplate layer; TH, Thalamus; VZ/SVZ, Ventricular/Subventricular Zone.
Nait-Oumesmar et al., 1999; Ligon et al., 2006; Menn et al., 2006).

We were interested whether Shh regulates the expression of Olig2 during human OLs development. For that purpose, we established mixed cell cultures of dorsal (CX) and ventral (GE) regions of $17 \mathrm{gw}$ forebrain. As expected from the results of immunostained cryosections, the density of Olig2 ${ }^{+}$cells was significantly higher in the ventral cultures compared to the dorsal (Figure 1D). Olig2 ${ }^{+}$cells represented $61 \%$ of total cells in ventral cultures compared to $38 \%$ in dorsal cultures $24 \mathrm{~h}$ postisolation (Figure 1D). The maintenance of Olig2 in cultured cells is in line with Olig2 expression reported in the majority of progenitor cells kept in defined medium with bFGF and EGF (Hack et al., 2004). As it was observed with other neural progenitors, the number of Olig2 ${ }^{+}$cells decreased progressively with the withdrawal of these growth factors, which led to cell differentiation (Gabay et al., 2003; Mo et al., 2007). At 21 days in vitro (DIV), density of Olig2 ${ }^{+}$cells was only $4 \%$ in both ventral and dorsal cell cultures (Figure 1D), which is a 15 and 10 times reduction respectively from their initial numbers.

Based on the observed pattern of expression and developmental changes of Olig2 ${ }^{+}$cells in tissue and in vitro, we concluded that dissociated human cell cultures represent a reliable model for the study of human OLs development.

\section{NEURAL CELL TYPES THAT EXPRESS Olig2 IN HUMAN CORTICAL CELL CULTURES}

In rodents, even though Olig2 is mainly expressed in OLs progenitors, its presence has also been reported in astrocyte precursors in the SVZ at early postnatal stages and in reactive astrocytes after injury (Marshall and Goldman, 2002; Cahoy et al., 2008). Moreover, several studies pointed out the importance of Olig2 in the generation of neurons in the ventral telencephalon (Petryniak et al., 2007) and in the spinal cord (Lu et al., 2002; Zhou and Anderson, 2002). Indeed, progress in genetic mapping studies in rodents indicates that during CNS development, the origin of oligodendroglial lineage is more closely associated to the neurons than to astrocytes (reviewed by Meijer et al., 2012). We reported previously that Olig2 was expressed not only in human fetal OPCs but also in MAP2 ${ }^{+}$ neurons (Jakovcevski and Zecevic, 2005). In the present study, we explored which cell types expressed Olig2 in the human fetal cortical cultures at midgestation. The expression of Olig2 was examined in cortical mixed cell cultures at $17 \mathrm{gw}$ according to the experimental design presented in Figure 2A. One day after seeding cortical cells, Olig2 was observed in early OPCs labeled with NG2 (Figure 2B). After 14 DIV Olig2 was present in early PDGFR $\alpha^{+}$OPCs (Figure 2C), in late OPCs marked with $\mathrm{O}^{+}$(Figure 2D), MAP2 ${ }^{+}$neurons (Figure 2E) and vimentin ${ }^{+}$ RGCs (Figure 2F). The same pattern of Olig2 distribution was 

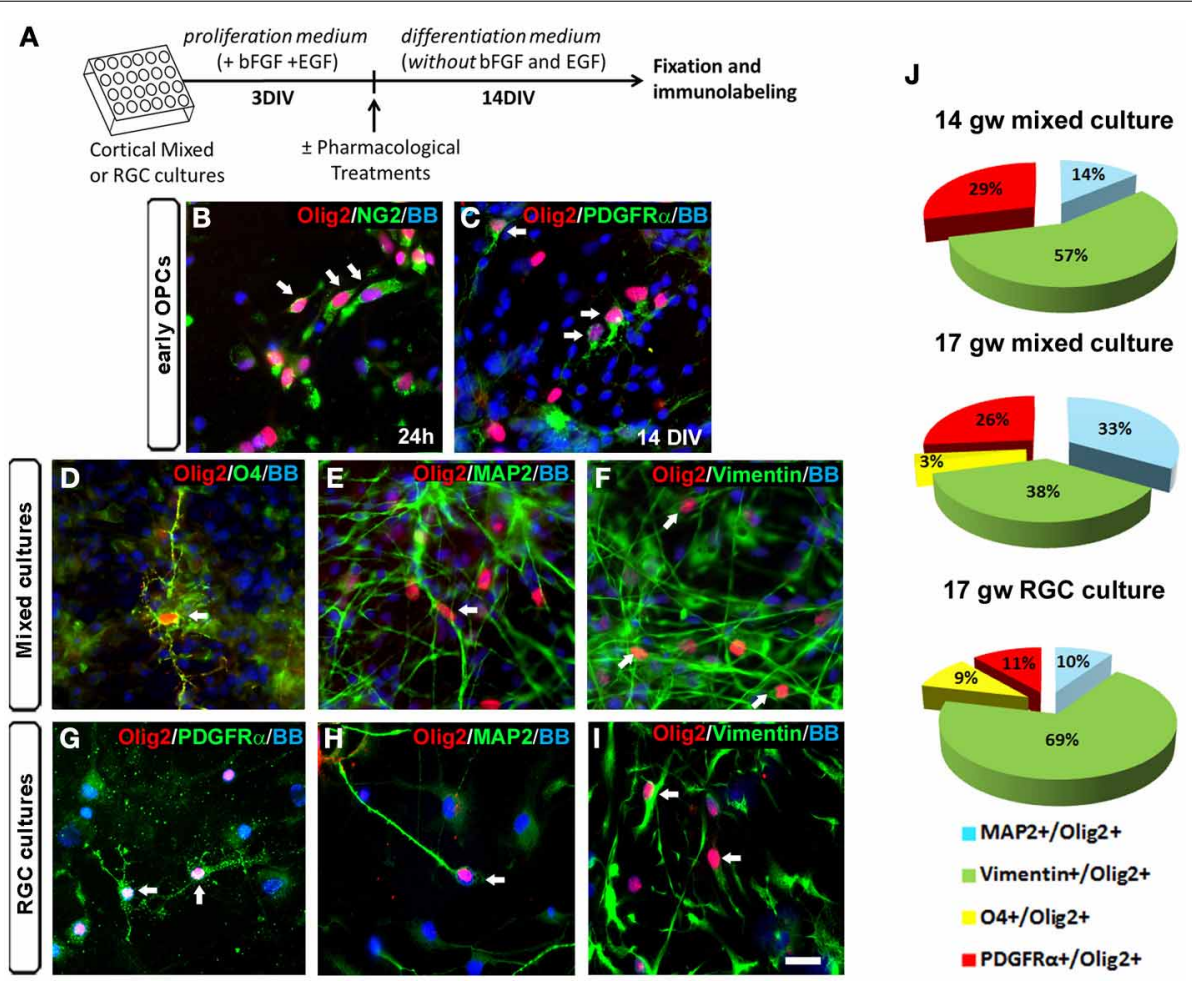

FIGURE 2 | Olig2 expression in human mixed and radial glia cell (RGC) cultures. (A) Time-line of the cell cultures protocol used. (B-I) Olig2 (red) expression in mixed cell cultures in $\mathrm{NG}^{+}$cells at $24 \mathrm{~h}$ (B) and in PDGFR $\alpha^{+}$ early OPCs at 14 DIV (C). Olig2 expression in mixed cell cultures at 14 DIV was observed in $\mathrm{O}^{+}{ }^{+}$late OPCs (D), in MAP2 ${ }^{+}$neurons (E) and in vimentin ${ }^{+}$
RGCs (F). Similar double-labeling results were demonstrated in RGC cultures after 14 DIV differentiation (G-I). Arrows show double-stained cells. (J) The percentages of neuronal (MAP2 $\left.{ }^{+}\right)$, RGC $\left(\right.$vimentin $\left.^{+}\right)$and OPCs (PDGFR $\alpha^{+}$, $\mathrm{O}^{+}$) cells from total Olig2 ${ }^{+}$cells in control mixed cell cultures (14 and $17 \mathrm{gw})$, and in $17 \mathrm{gw}$ RGC culture after 14 DIV. Scale bar: $20 \mu \mathrm{m}$. observed in enriched RGC cultures from the same case (17 gw) (Figures 2G-I).

We next analyzed differentiation of Olig $2^{+}$progenitors in cultures from two fetal brains, aged 14 and $17 \mathrm{gw}$. At $14 \mathrm{gw}$, in mixed cortical cultures after 14 DIV, $57 \%$ of Olig $2^{+}$cells were co-labeled with RGC marker vimentin, $14 \%$ with neuronal marker MAP2 ${ }^{+}$, $29 \%$ with early OPCs marker PDGFR $\alpha^{+}$and no cells were labeled with late OPC marker O4 (Figure 2J). In slightly older case (17 gw), the percentage of vimentin ${ }^{+} / \mathrm{Olig}^{+}$cells was reduced to $38 \% ; 33 \%$ were $\mathrm{MAP}^{+}, 26 \%$ were PDGFR $\alpha^{+}$and $3 \%$ were $\mathrm{O}^{+}$ (Figure 2J). These results, although obtained on a small number of cases, indicate that with increased fetal age from 14 to $17 \mathrm{gw}$, there is a decrease in vimentin ${ }^{+}$and an increase in density of $\mathrm{MAP}^{+}$cells within Olig2 ${ }^{+}$population of cells. Late ${ }^{+}{ }^{+} \mathrm{OPCs}$ although still sparse, were first demonstrated in $17 \mathrm{gw}$ mixed cultures. Obtained in vitro results suggest that there is a gradual differentiation of Olig2 ${ }^{+}$cells from multipotent RGC progenitors to neurons ( $19 \%$ more at 17 than at $14 \mathrm{gw}$ cultures) and from early OPCs to late OPCs. Age-dependent potential of $\mathrm{O}^{+}$preOLs production has also been recently reported by (Cui et al., 2012). These authors observed that sorted OPCs from older fetal tissue have increased myelination potential, which argues for the existence of intrinsic mechanisms controlling OLs differentiation and myelination (Cui et al., 2012). On the other hand, comparison between mixed cultures and RGC cultures at $17 \mathrm{gw}$ showed that the sum of Olig2 ${ }^{+}$early and late OPCs was reduced in RGC cultures $\left(11 \%\right.$ of PDGFR $\alpha^{+}$and $9 \%$ of $\left.4^{+}\right)$. As expected, the percentage of Olig2 ${ }^{+} /$RGCs was higher in RGC cultures (69\%) compared to the mixed cultures (38\%) (Figure 2J). In contrast, the percentage of $\mathrm{MAP}^{+}$neurons within Olig2 ${ }^{+}$population of cells was higher in mixed cell cultures (33\%) compared to the RGC cultures (10\%). These differences highlight the importance of distinct cellular support needed for OLs specification and differentiation that is present in mixed cell cultures and absent in enriched RGC culture. Indeed, the requirement of neurons and astrocytes to preserve OPCs proliferation and avoid their rapid loss in culture, as well as promote subsequent differentiation has been previously shown in multiple studies (Crang and Blakemore, 1997; Zhang et al., 2000; Filipovic and Zecevic, 2008; Emery, 2010; Monaco et al., 2012).

\section{EFFECT OF SHH ON Olig2 EXPRESSION}

OLs specification and differentiation can be modulated by intrinsic factors, such as Olig2, but also by extrinsic cues. One of these extrinsic factors is Shh, a potent morphogen secreted early during development by the notochord and floor plate and later on by progenitor cells in ventral (Pringle et al., 1996; Orentas et al., 1999) and dorsal telencephalic regions both in rodents (Gulacsi and Lillien, 2003; Komada et al., 2008) and in humans (Mo and Zecevic, 2009). Modulation of transcription factors expression, 
such as Olig1 and Olig2, by Shh is both necessary and sufficient to regulate initial oligodendrogenesis at the ventral telencephalon (Lu et al., 2000; Nery et al., 2001; Cai et al., 2005; Ligon et al., 2006; Petryniak et al., 2007). Later in development, OLs are generated in dorsal cortical regions in a process often considered to be Shhindependent (Nery et al., 2001; Cai et al., 2005; Vallstedt et al., 2005; Richardson et al., 2006). However, several studies in mice reported that Shh receptors, Patched 1 and Smoothened, are also expressed in dorsal cortical progenitor cells, and respond to Shh treatment by adopting OLs fate (Nery et al., 2001; Murray et al., 2002). Moreover, loss of function models of Shh and Olig1 and 2 demonstrated the importance of these extrinsic and intrinsic factors in regulation of ventrally and dorsally OLs derived populations, both in spinal cord and in forebrain (Lu et al., 2000; Kessaris et al., 2001, 2006; Fuccillo et al., 2006)

In contrast to the numerous reports on animal models, the effect of Shh signaling on OLs genesis in the human fetal brain remains elusive. Expression of Shh has been reported in human embryonic ventral spinal cord and mesencephalon (Hajihosseini et al., 1996; Orentas et al., 1999), and Shh mutation is related to brain defects such as holoprosencephaly or cyclopia (SchellApacik et al., 2003). Experimentally, these defects can be induced by the selective Shh inhibitor cyclopamine, a steroidal alkaloid known to interrupt Shh signaling by binding to its co-receptor Smoothened (Incardona et al., 1998). Previously, we reported that RGCs, isolated from human fetal forebrain at mid-term (20 gw), contain Shh and its receptors, Patchedl and Smoothened (Mo and Zecevic, 2009). Additionally, our unpublished results also demonstrate elements of a Gli signaling pathway in the human fetal cortical cultures (Radonjić et al., under revision). Notably, the capability of human RGC in vitro to generate cells of OL lineage can be modulated by Shh treatment (Mo and Zecevic, 2009). It would be particularly important to better understand the effect of Shh on dorsal oligodendrogenesis which probably plays a more significant role in the large human forebrain than in much smaller rodent brains.

We studied the effect of Shh treatment on Olig2 expression in mixed dissociated cultures obtained from human fetal cerebral cortex in four fetal brains $(14,17,18$, and $19 \mathrm{gw}$ ) (Figure 3A). Although we observed a trend of Shh-induced increase in the number of Olig2 ${ }^{+}$cells with progressively older cases, these values did not reach significance level. We, thus, combined four specimens together and compared them with controls (non Shh treated cultures). Treatment of cortical mixed cultures with Shh resulted in a significant increase in the number of Olig2 ${ }^{+}$cells, whereas treatment with Shh inhibitor, cyclopamine, did not affect the percentage of Olig2 ${ }^{+}$cells (Figure $3 \mathbf{A}$ ). In order to demonstrate that the effect of Shh on expression of Olig2 is specific, we also treated mixed cultures with both Shh and cyclopamine. This combined treatment did not change the number of Olig2 ${ }^{+}$cells compared to the control, and it inhibited the increase of Olig2 ${ }^{+}$ cells produced by the treatment with Shh alone (Figure 3A).

Similar results were observed in RGC cultures by Real-time PCR $(n=4 ; 14,17,17$, and $18 \mathrm{gw})$. Levels of Olig2 mRNA were higher in Shh-treated cultures but not in cyclopaminetreated cultures compared to control (Figure 3B). The finding that blocking endogenous Shh did not produce an effect, suggests

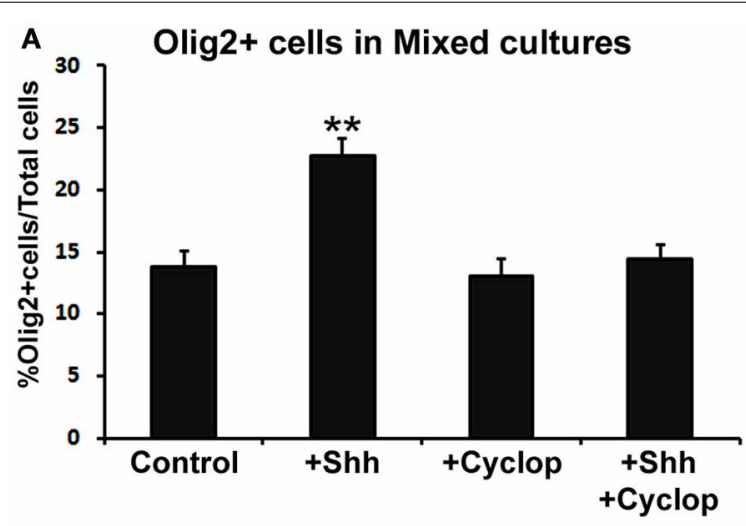

B Olig2 mRNA levels in RGC cultures

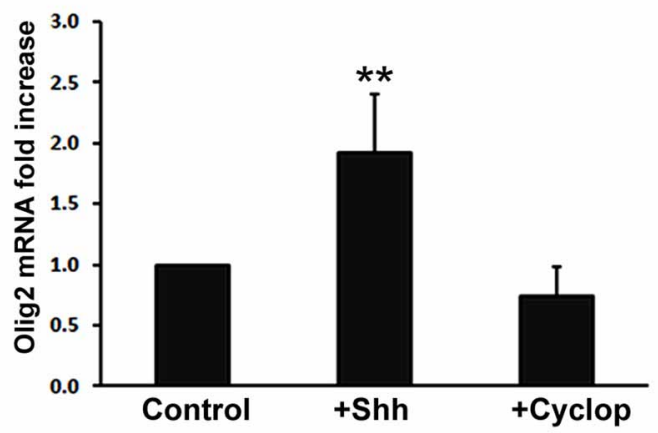

FIGURE 3 | The effect of Shh signaling on Olig2 expression in vitro. (A) Treatment with exogenous Shh significantly increased the percentage of Olig2 ${ }^{+}$cells from total cells in human cortical mixed cell cultures, whereas either cyclopamine or cyclopamine/Shh treatment did not show any effect ( $n=4 ; 14,17,18$, and $19 \mathrm{gw}$ mixed cultures). Data are presented as mean \pm s.e.m. ${ }^{* *} p<0.01$ vs. control. (B) Shh signaling modulated Olig2 mRNA levels in RGC cultures ( $n=4 ; 14$, two cases of 17 and $18 \mathrm{gw}$ ); cyclopamine treatment did not affect Olig2 mRNA levels. Data are presented as mean \pm standard deviation. ${ }^{* *} p<0.01$ vs. control.

an additional Shh-independent regulation of Olig2 expression in vitro. This is consistent with a previous report on different in vitro and in vivo requirements for Shh in oligodendrogenesis (Nery et al., 2001). A possible explanation is that in vivo Shh is necessary to overcome a constitutive inhibition for oligodendrogenesis that does not exist in vitro (Nery et al., 2001; Jakovcevski et al., 2009). Besides Shh, other factors such as bFGF (basic fibroblast growth factor), are implicated in OLs development (Kessaris et al., 2004; Furusho et al., 2011). bFGF and its receptor FGFR1 are constitutively expressed in astroglia and neurons in the cortex (Leadbeater et al., 2006) and bFGF acts synergistically with Shh inducing the expression of Olig2 and the generation of OLs from cortical progenitors in vitro (Kessaris et al., 2004). Hence, the difference in response to pharmacological treatments observed here may be due to the different endogenous expression levels of these molecules depending on the age and the brain region studied.

\section{SHH PROMOTES THE GENERATION OF OPC FROM RGC AND PRESERVES THEM IN UNDIFFERENTIATED STATE}

Animal studies showed that Shh increases the number of Olig2 progenitors probably by its well established function as 
a promoter of progenitor proliferation (Rowitch et al., 1999; Amankulor et al., 2009; Ferent et al., 2013). We analyzed the effect of Shh treatment on proliferation of Olig2 progenitors in mixed cortical cultures using proliferation marker Ki67 (Figure 4A). After $14 \mathrm{DIV}$, Shh treatment (Figure 2A) increased the number of cortical proliferative Olig $2^{+}$cells (Figure 4B). In mixed cultures treated with cyclopamine, or with combined Shh and cyclopamine, there was no change in the number of proliferating Olig2 ${ }^{+}$cells compared to the control (Figure 4B).

Next, we assessed the effect of Shh on early specification of cortical Olig2 ${ }^{+}$progenitors analyzing the percentages of neurons $\left(\mathrm{Olig}^{+} / \mathrm{MAP}^{+}\right)$, RGCs $\left(\mathrm{Olig} 2^{+} /\right.$vimentin $^{+}$), early OPCs $\left(\mathrm{Olig} 2^{+} / \mathrm{PDGFR}^{+}\right)$and late OPCs $\left(\mathrm{Olig} 2^{+} / \mathrm{O}^{+}\right)$ within the Olig2 ${ }^{+}$cell population (normalized to $100 \%$ in the chart, Figure 4C). We observed that exogenous Shh induced an increase of the number of early OPCs (Olig2 ${ }^{+} / \mathrm{PDGFR}^{+}$) by $9 \%$ (control, $26 \% \pm 3$; Shh, $35 \% \pm 2$ ) at the expense of RGC (Olig2 ${ }^{+} /$vimentin $^{+}$) which decreased by $10 \%$ (control, 38\% \pm 4 ; Shh, $28 \% \pm 2$ ) (Figure 4C). Treatment with cyclopamine or combined cyclopamine and Shh did not show significant difference in the number of Olig2 $2^{+} /$PDGFR $\alpha^{+}$cells and Olig $2^{+} /$vimentin ${ }^{+}$compared to control. The percentages of Olig2 expression in either MAP2 ${ }^{+}$neurons or $\mathrm{O}^{+}$late OPCs did not change among the treatments in $17 \mathrm{gw}$ cortical mixed cultures, indicating that Shh might specifically target early OPCs (Figure 4C).

Comparable results were obtained by Real-Time PCR analysis from 14, 17, and 18 gw RGC cultures. Parallel to the increase in Olig2 mRNA levels (Control, $1 \pm 0$; Shh, $1.7 \pm 0.3$; Fold increase mean \pm standard deviation), we observed that Shh treatment also enhances mRNA levels of PDGFR $\alpha$ (Control, $1 \pm 0$; Shh, $1.3 \pm$ $0.01)$. On the contrary, cyclopamine treatment resulted in a significant decrease in mRNA levels of PDGFR $\alpha(0.5 \pm 0.2)$ as well as in the mRNA levels of Olig2 $(0.7 \pm 0.3)$ in 2 of the 3 cases analyzed.

Thus, we showed here that Shh induced an increase in the number of proliferating Olig2 ${ }^{+}$cells as well as an increase in the total number of PDGFR $\alpha^{+} /$Olig $2^{+}$early OPCs, most likely at the expense of multipotent RG progenitors. Taking into consideration the low number of Olig $2^{+} / \mathrm{O} 4^{+}$cells obtained in our cultures, it is difficult to assess the effect of Shh on differentiation of Olig $2^{+}$progenitors further into oligodendroglial lineage at the stages studied here.

\section{WHICH CELLS IN OL LINEAGE ARE THE MOST RESPONSIVE TO SHH?}

To further clarify which progenitor cell type contributes the most to Shh response, we did a pilot study sorting two distinct cell populations from two fetal brains ( 14 and $17 \mathrm{gw}$ ): enriched RGC cultures (CD15 immunosorted cells) and OPC cultures (CD140a immunosorted cells). To confirm the identity of isolated cells, we performed immunostaining $24 \mathrm{~h}$ after isolation. For RGC that are $\mathrm{CD}_{15}{ }^{+}$, we used anti-BLBP antibody and for CD140a ${ }^{+}$cells we used anti-PDGFR $\alpha$ antibody (Figure 5A). In order to also assess a possible differential induction of Olig2 along OL lineage, both populations of sorted cells were then cultured for 18DIV with three distinct media that promote differentiation into different maturation stages of OLs lineage (Figure 5A): (a) control medium supplemented with B27 (B27), (b) medium supplemented with N2 and PDGFaa, a potent promotor of OPC proliferation (PDGF) (Hu et al., 2012), and (c) medium initially supplemented with N2 and PDGF and afterwards with NT3 and T3 (NT3+T3) to obtain late OPCs/early OLs (Dietrich et al., 2002; Dugas et al., 2006; Neri et al., 2010; Cui et al., 2012). We tested the effect of the three different media in RGC cultures, and as expected, PDGF medium produced the highest number of PDGFR $\alpha^{+}$cells (Figure 5B). In the NT3+T3 medium, where cells were exposed to PDGFaa for 2 days, we observed a significant increase in the number of PDGFR $\alpha^{+}$cells compared to the control, B27 medium. The highest levels of $\mathrm{O}^{+}$cells were observed in NT3+T3 maturation medium (Figure 5B). These results confirmed the effects of PDGFaa and NT3+T3 on OPC proliferation and maturation respectively.

We next showed that in RGC cultures Olig2 protein levels increased after the Shh treatment regardless of the culture medium, while no changes were observed in OPC cultures (Figure 5C). This difference suggests that RGC progenitors are more susceptible to Shh and increase their Olig2 content in response to Shh treatment. The highest level of Olig2 after Shh treatment was demonstrated in PDGF medium (Figure 5C). Under these conditions the number of early OPCs $\left(\mathrm{PDGFR} \alpha^{+}\right)$ was also the highest (Figure 5B). This result indicates that Shh and PDGF might synergistically promote the differentiation of RGCs into OPCs, through the increase in the expression of Olig2. The lack of induction in OPC cultures might indicate that once cells are committed to OL fate, they do not upregulate Olig2 in response to Shh. Similar in vitro results were reported for mouse embryonic stem cells. Treatment with Shh induced Olig2 expression in progenitor cells until oligodendrogenesis starts, but Shh was not required for the differentiation into later stages of OL lineage (Du et al., 2006). Similarly, in the spinal cord Shh also promotes proliferation of selected CNS precursors and blocked their differentiation (Rowitch et al., 1999).

\section{SUBCELLULAR LOCALIZATION AND FUNCTION OF Olig2 IN HUMAN DEVELOPING OLS}

We observed that Olig2 expression was generally nuclear in various cell types, consistent with its role as a transcription factor. However, with the progression of OLs development, Olig2 can also be observed in the soma of the cells. In late OPCs, labeled with $\mathrm{O} 4$ antibody, Olig2 is observed in the increasingly ramified cell processes in contrast to a restricted nuclear localization in early OPCs (Figure 6A). This finding supports our previous results on cellular localization of Olig2 in the human developing brain (Jakovcevski and Zecevic, 2005; Jakovcevski et al., 2009). The control of subcellular localization of transcription factors is considered to represent a regulatory mechanism of many signaling pathways (Ziegler and Ghosh, 2005). Thus, different subcellular localization of Olig2 at different OL maturation stages might be due to a different requirement of this transcription factor during OLs development. Recent reports on conditional knock out animals demonstrate that deletion of Olig2 in OLs progenitors $\left(\mathrm{CNP}^{+}\right.$cells $)$dramatically reduces differentiation into OLs, whereas Olig2 ablation in mature OLs $\left(\mathrm{PLP}^{+}\right)$enhances 

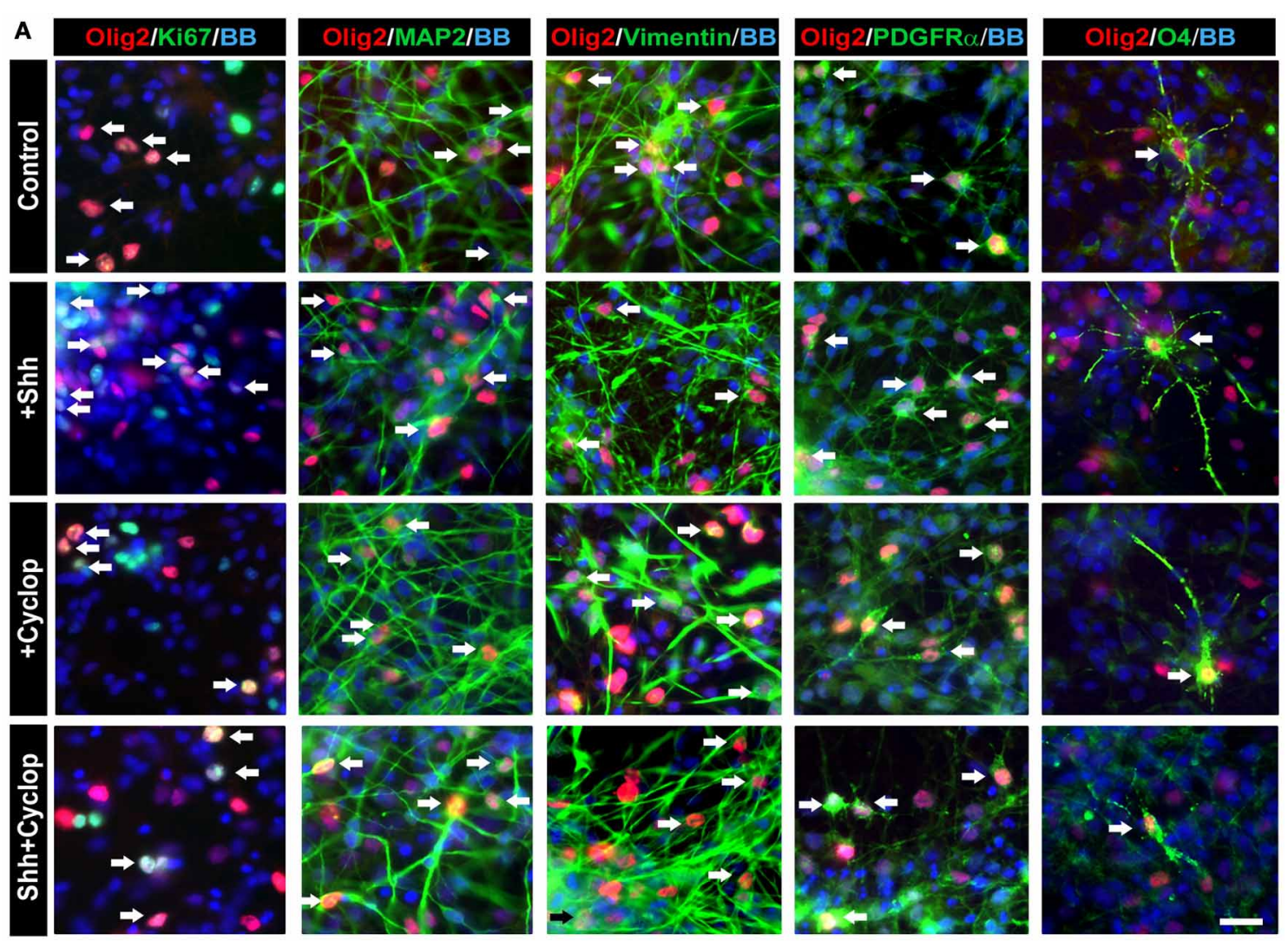

B

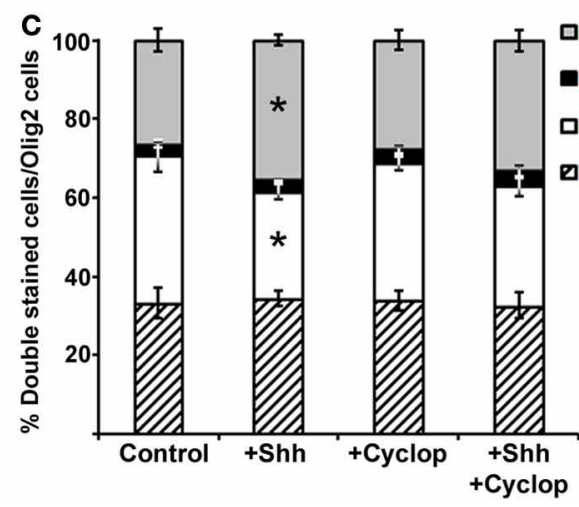

口PDGFRa+/Olig2+ - $04+$ +Olig2+ 口Vimentin+/Olig2+ DMAP2+/Olig2+

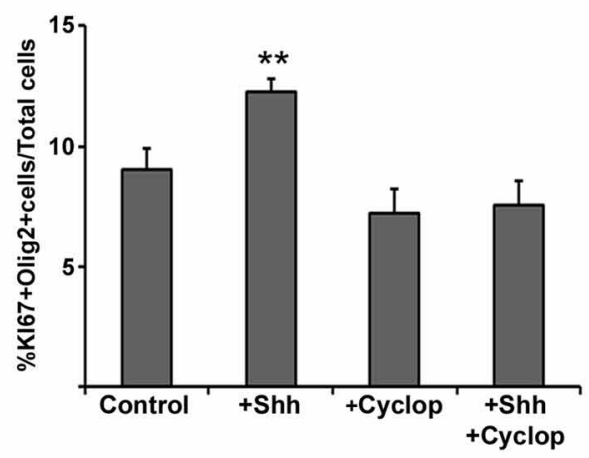

FIGURE 4 | The effect of Shh signaling on proliferation and differentiation of Olig2 ${ }^{+}$cells in vitro. (A) In mixed cell cultures at midgestation, Olig2 ${ }^{+}$cells (red) were co-labeled with Ki67 (cell proliferation marker), MAP2 (neuronal marker), vimentin (RGC marker), PDGFR $\alpha$ (early OPC marker) and $\mathrm{O} 4$ (late OPC marker) in green. Nuclear staining with bisbenzimide (BB) in blue. Scale bar: $20 \mu \mathrm{m}$. (B) Proliferation of Olig2 ${ }^{+}$ cells, estimated by double-labeling with Ki67, increased after Shh treatment, but did not change after either cyclopamine or combined cyclopamine and Shh treatments. (C) The composition of Olig2 ${ }^{+}$cell population in $17 \mathrm{gw}$ cortical mixed cell cultures changed with manipulation of Shh signaling. Graph shows the percentage of Olig2 ${ }^{+}$neurons (Olig2 $\left.{ }^{+} / \mathrm{MAP}^{+}{ }^{+}\right), \mathrm{RGCs}\left(\mathrm{Olig} 2^{+}\right.$Nimentin ${ }^{+}$) or early (Olig2 ${ }^{+} / \mathrm{PDGFR}^{+}$) and late $\left(\mathrm{Olig} 2^{+} / \mathrm{O}^{+}\right)$OPCs out of the total number of Olig2 ${ }^{+}$cells; note the selective increase of Olig2/PDGFR $\alpha^{+}$cells and the proportional decrease of Olig2/vimentin ${ }^{+}$cells after Shh treatment. Data are presented as mean \pm s.e.m. ${ }^{*} p<0.05,{ }^{* *} p<0.01$ vs. control. maturation and increases myelination (Mei et al., 2013). This key role of Olig2 in OL specification and maturation might clarify why the transplantation of Olig2-overexpressing neural stem cells into demyelinating lesions significantly enhances the generation of OL but has only modest effects on remyelination (Copray et al., 2006; Maire et al., 2009; Kim et al., 2011; Hu et al., 2012).

\section{CONCLUDING REMARKS}

Numerous developmental studies tried to clarify regulatory mechanisms of Shh and Olig2 on oligodendrogenesis in animal models, but similar studies have not been done in developing human brain. We demonstrated that Shh promotes an expansion of human cortical progenitors, similar to its effect in rodents. Shh also influences progenitor fate by enlarging the pool of 


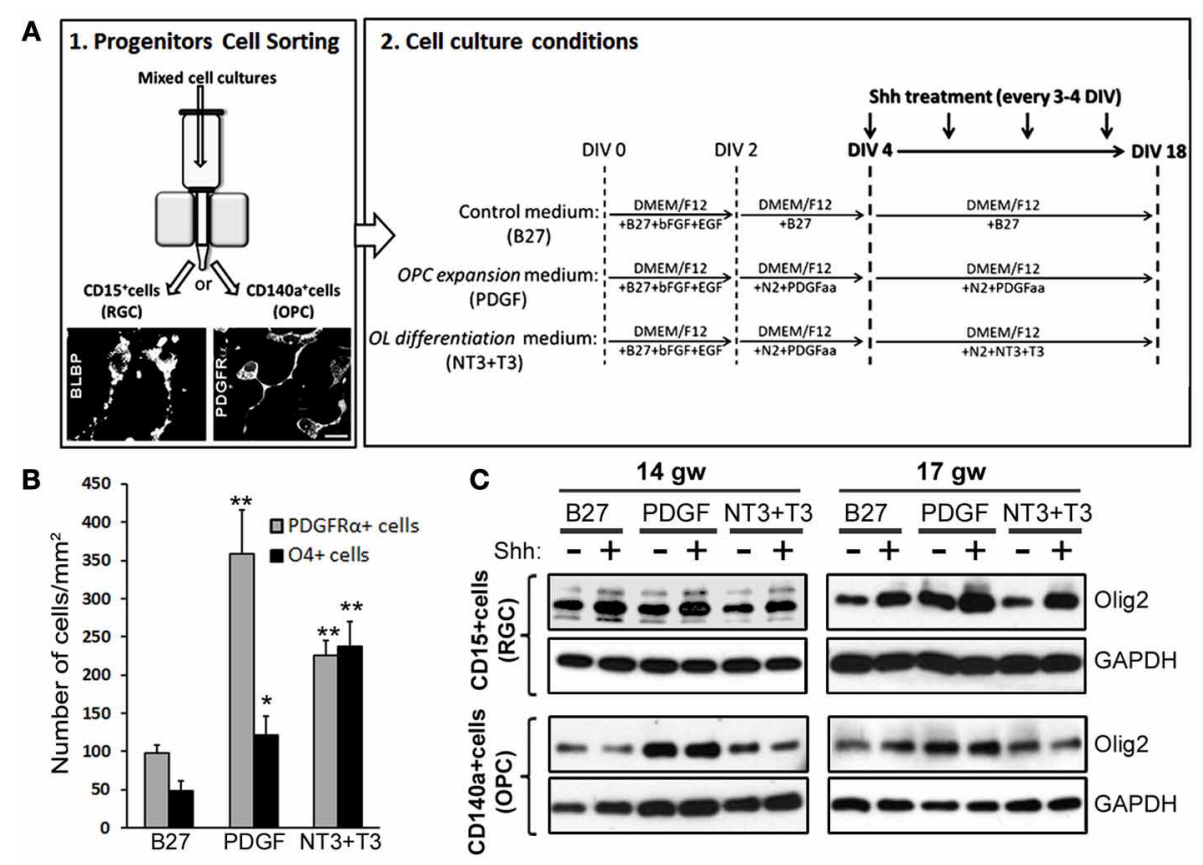

FIGURE 5 | The effect of Shh on selected cortical progenitors obtained from 14 and $17 \mathrm{gw}$ cerebral cortex. (A) Scheme of the protocol for the immunosorting of human RGCs $\left(\mathrm{CD} 15^{+}\right)$and OPCs $\left(\mathrm{CD} 140 \mathrm{a}^{+}\right)$;

Representative image of BLBP ${ }^{+}$RGCs and PDGFR $\alpha^{+}$early OPCs, $24 \mathrm{~h}$ after immunosorting. Sorted cells were cultured in three different media: Control medium (B27), PDGF and NT3+T3 media, and treated with Shh from

4-18 DIV. (B) Number of PDGFR $\alpha^{+}$cells and $\mathrm{O}^{+}$cells per surface area in 17 gw RGCs cultures with control (B27), OPC expansion (PDGF) and OLs differentiation (NT3+T3) medium. (C) Protein levels of Olig2 measured by Western blot in RGCs and OPCs cultures with and without Shh treatment in the three different media. The increase levels of Olig2 protein was only observed in RGC cultures, being specially high in OPC expansion medium, and not in OPC cultures; GAPDH-loading control. Data are presented as mean \pm s.e.m. ${ }^{*} p<0.05,{ }^{* *} p<0.01$ vs. control.
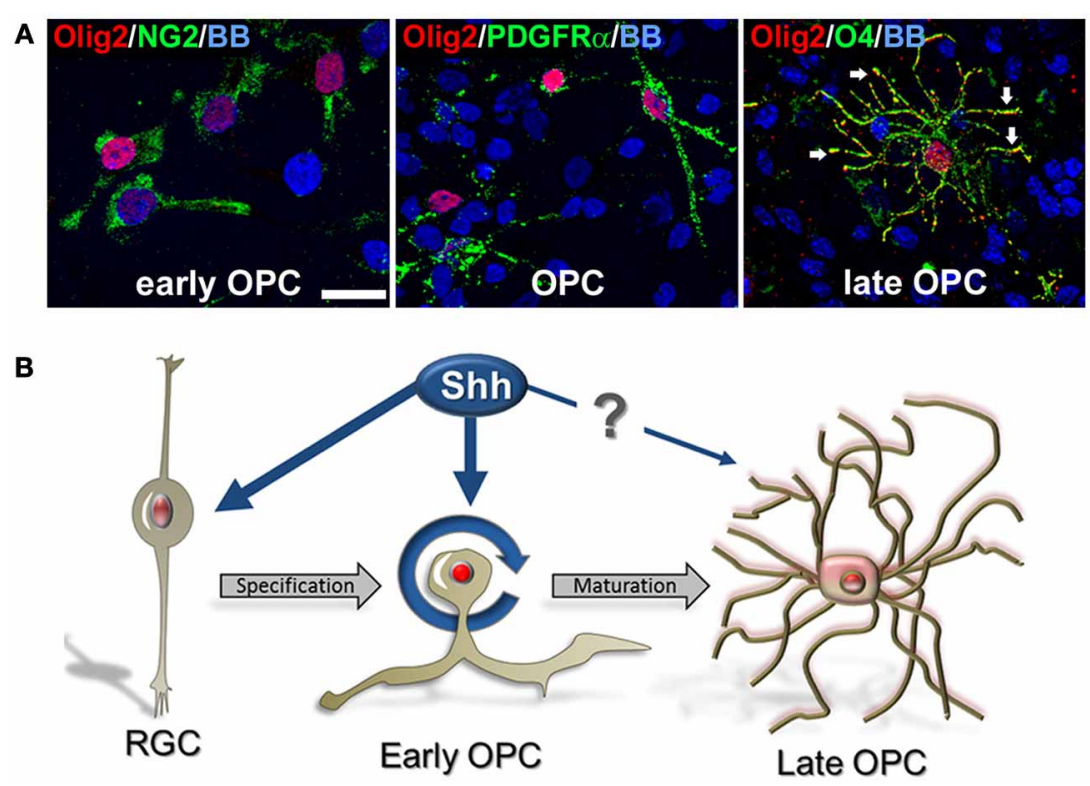

Early OPC

Olig2 expression (red) along the OLs lineage in human fetal cortical

FIGURE 6 | Cellular distribution of Olig2 in different cell types. (A) Nuclear expression in early OPCs NG2 ${ }^{+}(1 \mathrm{DIV})$ and PDGFR $\alpha^{+}$(14DIV) cells and cytosolic expression in $\mathrm{O}^{+}$late OPCs/immature OLs (14DIV) (arrows). Nuclear staining with bisbenzimide (BB) in blue. Scale bar: $20 \mu \mathrm{m}$. (B) Schematic presentation of the possible effect of Shh on cultures. Shh might actively participate in proliferation and specification of early OPCs from RGCs in the cerebral cortex. However, the effect of Shh and Olig2 in the differentiation of early OPCs to mature OLs might not be required. 
Olig2 ${ }^{+} / \mathrm{PDGFR}^{+}$early OPCs. Based on our results we propose that Shh might actively participate in proliferation and specification of early cortical OPCs from RGCs, but its role in the transition from early OPCs to mature OLs is still unclear (Figure 6B). Better understanding of Shh and Olig2 function in human OL development is a critical point in developing new therapeutic targets for demyelinating diseases.

\section{ACKNOWLEDGMENTS}

This study was supported by the National Society for Multiple Sclerosis Grant (RG 3083-D-5) and R01 NSO41489. We are thankful to Dr. I. Jakovcevski for immunohistochemical tissue staining and Nicole Glidden for technical support and editing.

\section{REFERENCES}

Amankulor, N. M., Hambardzumyan, D., Pyonteck, S. M., Becher, O. J., Joyce, J. A., and Holland, E. C. (2009). Sonic hedgehog pathway activation is induced by acute brain injury and regulated by injury-related inflammation. J. Neurosci. 29, 10299-10308. doi: 10.1523/JNEUROSCI.250009.2009

Arnett, H. A., Fancy, S. P., Alberta, J. A., Zhao, C., Plant, S. R., Kaing, S., et al. (2004). bHLH transcription factor Olig1 is required to repair demyelinated lesions in the CNS. Science 306, 2111-2115. doi: 10.1126/science.1103709

Back, S. A., Luo, N. L., Borenstein, N. S., and Levine, H. C. (2001). Late oligodendrocyte progenitors coincide with the developmental widow of vulnerability for human perinatal white matter injury. J. Neurosci. 21, 1302-1312.

Balaskas, N., Ribeiro, A., Panovska, J., Dessaud, E., Sasai, N., Page, K. M., et al. (2012). Gene regulatory logic for reading the Sonic Hedgehog signaling gradient in the vertebrate neural tube. Cell 148, 273-284. doi: 10.1016/j.cell.2011.10.047

Buffo, A., Vosko, M. R., Ertürk, D., Hamann, G. F., Jucker, M., Rowitch, D., et al. (2005). Expression pattern of the transcription factor Olig2 in response to brain injuries: Implications for neuronal repair. Proc. Natl. Acad. Sci. U.S.A. 102, 18183-18188. doi: 10.1073/pnas.0506535102

Cahoy, J. D., Emery, B., Kaushal, A., Foo, L. C., Zamanian, J. L., Christopherson, K. S., et al. (2008). A transcriptome database for astrocytes, neurons, and oligodendrocytes: a new resource for understanding brain development and function. J. Neurosci. 28, 264-278. doi: 10.1523/JNEUROSCI.4178-07.2008

Cai, J., Qi, Y., Hu, X., Tan, M., Liu, Z., Zhang, J., et al. (2005). Generation of oligodendrocyte precursor cells from mouse dorsal spinal cord independent of Nkx6 regulation and Shh signaling. Neuron 45, 41-53. doi: 10.1016/j.neuron.2004.12.028

Casper, K. B., and Mccarthy, K. D. (2006). GFAP-positive progenitor cells produce neurons and oligodendrocytes throughout the CNS. Mol. Cell. Neurosci. 31, 676-684. doi: 10.1016/j.mcn.2005.12.006

Copray, S., Balasubramaniyan, V., Levenga, J., De Bruijn, J., Liem, R., and Boddeke, E. (2006). Olig2 overexpression induces the in vitro differentiation of neural stem cells into mature oligodendrocytes. Stem Cells 24, 1001-1010. doi: 10.1634/stemcells.2005-0239

Crang, A. J., and Blakemore, W. F. (1997). Attempts to produce astrocyte cultures devoid of oligodendrocyte generating potential by the use of antimitotic treatment reveal the presence of quiescent oligodendrocyte precursors. J. Neurosci. Res. 49, 64-71.

Cui, Q. L., D’abate, L., Fang, J., Leong, S. Y., Ludwin, S., Kennedy, T. E., et al. (2012). Human fetal oligodendrocyte progenitor cells from different gestational stages exhibit substantially different potential to myelinate. Stem Cells Dev. 21, 1831-1837. doi: 10.1089/scd.2011.0494

De Castro, F., and Bribián, A. (2005). The molecular orchestra of the migration of oligodendrocyte precursors during development. Brain Res. Rev. 49, 227-241. doi: 10.1016/j.brainresrev.2004.12.034

Dietrich, J., Noble, M., and Mayer-Proschel, M. (2002). Characterization of A2B5+ glial precursor cells from cryopreserved human fetal brain progenitor cells. Glia 40, 65-77. doi: 10.1002/glia.10116

Du, Z. W., Li, X. J., Nguyen, G. D., and Zhang, S. C. (2006). Induced expression of Olig2 is sufficient for oligodendrocyte specification but not for motoneuron specification and astrocyte repression. Mol. Cell. Neurosci. 33, 371-380. doi: 10.1016/j.mcn.2006.08.007
Dugas, J. C., Tai, Y. C., Speed, T. P., Ngai, J., and Barres, B. A. (2006). Functional genomic analysis of oligodendrocyte differentiation. J. Neurosci. 26, 10967-10983. doi: 10.1523/JNEUROSCI.2572-06.2006

Emery, B. (2010). Regulation of oligodendrocyte differentiation and myelination. Science 330, 779-782. doi: 10.1126/science.1190927

Fancy, S. P., Zhao, C., and Franklin, R. J. (2004). Increased expression of Nkx2.2 and Olig2 identifies reactive oligodendrocyte progenitor cells responding to demyelination in the adult CNS. Mol. Cell. Neurosci. 27, 247-254. doi: 10.1016/j.mcn.2004.06.015

Ferent, J., Zimmer, C., Durbec, P., Ruat, M., and Traiffort, E. (2013). Sonic Hedgehog signaling is a positive oligodendrocyte regulator during demyelination. J. Neurosci. 33, 1759-1772. doi: 10.1523/JNEUROSCI.3334-12.2013

Filipovic, R., and Zecevic, N. (2008). The effect of CXCL1 on human fetal oligodendrocyte progenitor cells. Glia 56, 1-15 doi: 10.1002/glia.20582

Fogarty, M., Richardson, W. D., and Kessaris, N. (2005). A subset of oligodendrocytes generated from radial glia in the dorsal spinal cord. Development 132, 1951-1959. doi: 10.1242/dev.01777

Fuccillo, M., Rutlin, M., and Fishell, G. (2006). Removal of Pax6 partially rescues the loss of ventral structures in Shh null mice. Cereb. Cortex 16(Suppl. 1), i96-i102. doi: 10.1093/cercor/bhk023

Furusho, M., Kaga, Y., Ishii, A., Hebert, J. M., and Bansal, R. (2011). Fibroblast growth factor signaling is required for the generation of oligodendrocyte progenitors from the embryonic forebrain. J. Neurosci. 31, 5055-5066. doi: 10.1523/JNEUROSCI.4800-10.2011

Gabay, L., Lowell, S., Rubin, L. L., and Anderson, D. J. (2003). Deregulation of dorsoventral patterning by FGF confers trilineage differentiation capacity on CNS stem cells in vitro. Neuron 40, 485-499. doi: 10.1016/S08966273(03)00637-8

Georgieva, L., Moskvina, V., Peirce, T., Norton, N., Bray, N. J., Jones, L., et al. (2006). Convergent evidence that oligodendrocyte lineage transcrition factor 2 (OLIG2) and interacting genes influence susceptibility to schizophrenia. Proc. Natl. Acad. Sci. U.S.A. 103, 12469-12474. doi: 10.1073/pnas.0603029103

Goldman, S. A., Nedergaard, M., and Windrem, M. S. (2012). Glial progenitor cellbased treatment and modeling of neurological disease. Science 338, 491-495. doi: $10.1126 /$ science. 1218071

Gorski, J. A., Talley, T., Qiu, M., Puelles, L., Rubenstein, J. L., and Jones, K. R. (2002). Cortical excitatory neurons and glia, but not GABAergic neurons, are produced in the Emxl-expressing lineage. J. Neurosci. 22, 6309-6314.

Gritli-Linde, A., Lewis, P., Mcmahon, A. P., and Linde, A. (2001). The whereabouts of a morphogen: direct evidence for short- and graded longrange activity of hedgehog signaling peptides. Dev. Biol. 236, 364-386. doi: 10.1006/dbio. 2001.0336

Gulacsi, A., and Lillien, L. (2003). Sonic hedgehog and bone morphogenetic protein regulate interneuron development from dorsal telencephalic progenitor.pdf $>$. J. Neurosci. 23, 9862-9872.

Hack, M. A., Sugimori, M., Lundberg, C., Nakafuku, M., and Götz, M. (2004). Regionalization and fate specification in neurospheres: the role of Olig2 and Pax6. Mol. Cell. Neurosci. 25, 664-678. doi: 10.1016/j.mcn.2003.12.012

Hajihosseini, M., Tham, T. N., and Dubois-Dalcq, M. (1996). Origin of oligodendrocytes within the human spinal cord. J. Neurosci. 16, 7981-7994.

He, W., Ingraham, C., Rising, L., Goderie, S., and Temple, S. (2001). Multipotent stem cells from the mouse basal forebrain contribute GABAergic neurons and oligodendrocytes to the cerebral cortex during embryogenesis. J. Neurosci. 21, 8854-8862.

Hu, J. G., Shen, L., Wang, R., Wang, Q. Y., Zhang, C., Xi, J., et al. (2012). Effects of Olig2-overexpressing neural stem cells and myelin basic protein-activated $\mathrm{T}$ cells on recovery from spinal cord injury. Neurotherapeutics 9, 422-445. doi: 10.1007/s13311-011-0090-9

Incardona, J. P., Gaffield, W., Kapur, R. P., and Roelink, H. (1998). The teratogenic Veratrum alkaloid cyclopamine inhibits sonic hedgehog signal transduction. Development 125, 3553-3562.

Jacobs, E. C., Campagnoni, C., Kampf, K., Reyes, S. D., Kalra, V., Handley, V., et al. (2007). Visualization of corticofugal projections during early cortical development in a $\tau$-GFP-transgenic mouse. Eur. J. Neurosci. 25, 17-30. doi: 10.1111/j.1460-9568.2006.05258.x

Jakovcevski, I., Filipovic, R., Mo, Z., Rakic, S., and Zecevic, N. (2009). Oligodendrocyte development and the onset of myelination in the human fetal brain. Front. Neuroanat. 3:5. doi: 10.3389/neuro.05.005.2009 
Jakovcevski, I., and Zecevic, N. (2005). Sequence of oligodendrocyte development in the human fetal telencephalon. Glia 49, 480-491. doi: 10.1002/glia.20134

Kessaris, N., Fogarty, M., Iannarelli, P., Grist, M., Wegner, M., and Richardson, W. D. (2006). Competing waves of oligodendrocytes in the forebrain and postnatal elimination of an embryonic lineage. Nat. Neurosci. 9, 173-179. doi: $10.1038 / \mathrm{nn} 1620$

Kessaris, N., Jamen, F., Rubin, L. L., and Richardson, W. D. (2004). Cooperation between sonic hedgehog and fibroblast growth factor/MAPK signalling pathways in neocortical precursors. Development 131, 1289-1298. doi: $10.1242 /$ dev.01027

Kessaris, N., Pringle, N., and Richardson, W. D. (2001). Ventral neurogenesis and the neuron-glial switch. Neuron 31, 677-680. doi: 10.1016/S08966273(01)00430-5

Kessaris, N., Pringle, N., and Richardson, W. D. (2008). Specification of CNS glia from neural stem cells in the embryonic neuroepithelium. Philos. Trans. R. Soc. Lond. B Biol. Sci. 363, 71-85. doi: 10.1098/rstb.2006.2013

Kim, H. M., Hwang, D. H., Choi, J. Y., Park, C. H., Suh-Kim, H., Kim, S. U., et al. (2011). Differential and cooperative actions of Olig1 and Olig2 transcription factors on immature proliferating cells after contusive spinal cord injury. Glia 59, 1094-1106. doi: 10.1002/glia.21182

Komada, M., Saitsu, H., Kinboshi, M., Miura, T., Shiota, K., and Ishibashi, M. (2008). Hedgehog signaling is involved in development of the neocortex. Development 135, 2717-2727. doi: 10.1242/dev.015891

Kostovic, I., and Rakic, P. (1990). Development history of the transient subplate zone in the visual and somatosensory cortex of the macaque monkey and human brain. J. Comp. Neurol. 297, 441-470. doi: 10.1002/cne. 902970309

Kriegstein, A., and Alvarez-Buylla, A. (2009). The glial nature of embryonic and adult neural stem cells. Annu. Rev. Neurosci. 32, 149-184. doi: 10.1146/annurev.neuro.051508.135600

Leadbeater, W. E., Gonzalez, A. M., Logaras, N., Berry, M., Turnbull, J. E., and Logan, A. (2006). Intracellular trafficking in neurones and glia of fibroblast growth factor-2, fibroblast growth factor receptor 1 and heparan sulphate proteoglycans in the injured adult rat cerebral cortex. J. Neurochem. 96, 1189-1200. doi: 10.1111/j.1471-4159.2005.03632.x

Levison, S. W., and Goldman, J. E. (1993). Both oligodendrocytes and astrocytes develop from progenitors in the subventricular zone of postnatal rat forebrain. Neuron 10, 201-212. doi: 10.1016/0896-6273(93)90311-E

Ligon, K. L., Alberta, J. A., Kho, A. T.,Weiss, J., Kwaan, M.R., Nutt, C. L., et al. (2004). The oligodendroglial lineage marker OLIG2 is universally expressed in diffuse gliomas. J. Neuropathol. Exp. Neurol. 63, 499-509.

Ligon, K. L., Fancy, S. P., Franklin, R. J., and Rowitch, D. H. (2006). Olig gene function in CNS development and disease. Glia 54, 1-10. doi: 10.1002/glia.20273

Lu, Q. R., Sun, T., Zhu, Z., Ma, N., Garcia, M., Stiles, C. D., et al. (2002). Common developmental requirement for Olig function indicates a motor neuron/oligodendrocyte connection. Cell 109, 75-86. doi: 10.1016/S00928674(02)00678-5

Lu, Q. R., Yuk, D., Alberta, J. A., Zhu, Z., Pawlitzky, I., Chan, J., et al. (2000). Sonic hedgehog-regulated oligodendrocyte lineage genes encoding bHLH proteins in the mammalian central nervous system. Neuron 25, 317-329. doi: 10.1016/S0896-6273(00)80897-1

Maire, C. L., Buchet, D., Kerninon, C., Deboux, C., Baron-Van Evercooren, A., and Nait-Oumesmar, B. (2009). Directing human neural stem/precursor cells into oligodendrocytes by overexpression of Olig2 transcription factor. J. Neurosci. Res. 87, 3438-3446. doi: 10.1002/jnr.22194

Marshall, C. A., and Goldman, J. E. (2002). Subpallial dlx2-expressing cells give rise to astrocytes and oligodendrocytes in the cerebral cortex and white matter. J. Neurosci. 22, 9821-9830.

Marti, E., and Bovolenta, P. (2002). Sonic hedgehog in CNS development: one signal, multiple outputs. Trends Neurosci. 25, 89-96. doi: 10.1016/S01662236(02)02062-3

McConnell, S. K., Ghosh, A., and Shatz, C. J. (1989). Subplate neurons pioneer the first axon pathway from the cerebral cortex. Science 245, 978-982. doi: $10.1126 /$ science. 2475909

Mei, F., Wang, H., Liu, S., Niu, J., Wang, L., He, Y., et al. (2013). Stage-specific deletion of olig2 conveys opposing functions on differentiation and maturation of oligodendrocytes. J. Neurosci. 33, 8454-8462. doi: 10.1523/JNEUROSCI.245312.2013
Meijer, D. H., Kane, M. F., Mehta, S., Liu, H., Harrington, E., Taylor, C. M., et al. (2012). Separated at birth? The functional and molecular divergence of OLIG1 and OLIG2. Nat. Rev. Neurosci. 13, 819-831. doi: 10.1038/ nrn3386

Menn, B., Garcia-Verdugo, J. M., Yaschine, C., Gonzalez-Perez, O., Rowitch, D., and Alvarez-Buylla, A. (2006). Origin of oligodendrocytes in the subventricular zone of the adult brain. J. Neurosci. 26, 7907-7918. doi: 10.1523/JNEUROSCI.129906.2006

Mo, Z., Moore, A. R., Filipovic, R., Ogawa, Y., Kazuhiro, I., Antic, S. D., et al. (2007). Human cortical neurons originate from radial glia and neuron-restricted progenitors. J. Neurosci. 27, 4132-4145. doi: 10.1523/JNEUROSCI.0111-07.2007

Mo, Z., and Zecevic, N. (2009). Human fetal radial glia cells generate oligodendrocytes in vitro. Glia 57, 490-498. doi: 10.1002/glia.20775

Monaco, M. C., Maric, D., Bandeian, A., Leibovitch, E., Yang, W., and Major, E. O. (2012). Progenitor-derived oligodendrocyte culture system from human fetal brain. J. Vis. Exp. e4274. doi: 10.3791/4274

Murray, K., Calaora, V., Rottkamp, C., Guicherit, O., and Dubois-Dalcq, M. (2002). Sonic hedgehog is a potent inducer of rat oligodendrocyte development from cortical precursors in vitro. Mol. Cell. Neurosci. 19, 320-332. doi: $10.1006 /$ mcne.2001.1079

Nait-Oumesmar, B., Decker, L., Lachapelle, F., Avellana-Adalid, V., Bachelin, C., and Baron-Van Evercooren, A. (1999). Progenitor cells of the adult mouse subventricular zone proliferate, migrate and differentiate into oligodendrocytes after demyelination. Eur. J. Neurosci. 11, 4357-4366. doi: 10.1046/j.14609568.1999.00873.x

Neri, M., Maderna, C., Ferrari, D., Cavazzin, C., Vescovi, A. L., and Gritti, A. (2010). Robust generation of oligodendrocyte progenitors from human neural stem cells and engraftment in experimental demyelination models in mice. PLoS ONE 5:e10145. doi: 10.1371/journal.pone.0010145

Nery, S., Wichterle, H., and Fishell, G. (2001). Sonic hedgehog contributes to oligodendrocyte specification in the mammalian forebrain. Development 128 , 527-540.

Nicolay, D. J., Doucette, J. R., and Nazarali, A. J. (2007). Transcriptional control of oligodendrogenesis. Glia 55, 1287-1299. doi: 10.1002/glia.20540

Orentas, D. M., Hayes, J. E., Dyer, K. L., and Miller, R. H. (1999). Sonic hedgehog signaling is required during the appearance of spinal cord oligodendrocyte precursors. Development 126, 2419-2429.

Petryniak, M. A., Potter, G. B., Rowitch, D. H., and Rubenstein, J. L. (2007). Dlx1 and Dlx2 control neuronal versus oligodendroglial cell fate acquisition in the developing forebrain. Neuron 55, 417-433. doi: 10.1016/j.neuron.2007.06.036

Pfeiffer, S. E., Warrington, A. E., and Bansal, R. (1993). The oligodendrocyte and its many cellular processes. Trends Cell Biol. 3, 191-197. doi: 10.1016/09628924(93)90213-K

Pringle, N. P., Yu, W.-P., Guthrie, S., Roelink, H., Lumsden, A., Peterson, A. C. et al. (1996). Determination of neuroepithelial cell fate: induction of the oligodendrocyte lineage by ventral midline cells and sonic hedgehog. Dev. Biol. 177, 30-42. doi: 10.1006/dbio.1996.0142

Raff, M. C., Durand, B., and Gao, F. B. (1998). Cell number control and timing in animal development: the oligodendrocyte cell lineage. Int. J. Dev. Biol. 42, 263-267.

Rakic, S., and Zecevic, N. (2003). Early oligodendrocyte progenitor cells in the human fetal telencephalon. Glia 41, 117-127. doi: 10.1002/glia.10140

Rao, M. S., Noble, M., and Mayer-Proschel, M. (1998). A tripotential glial precursor cell is present in the developing spinal cord. Proc. Natl. Acad. Sci. U.S.A. 95, 3996-4001. doi: 10.1073/pnas.95.7.3996

Richardson, W. D., Kessaris, N., and Pringle, N. (2006). Oligodendrocyte wars. Nat. Rev. Neurosci. 7, 11-18. doi: 10.1038/nrn1826

Rivkin, M. J., Flax, J., Mozell, R., Osathanondh, R., Volpe, J. J., and Villa-Komaroff, L. (1995). Oligodendroglial development in human fetal cerebrum. Ann. Neurol. 38, 92-101. doi: 10.1002/ana.410380116

Rowitch, D. H., S-Jacques, B., Lee, S. M., Flax, J. D., Snyder, E. Y., and McMahon, A. P. (1999). Sonic hedgehog regulates proliferation and inhibits differentiation of CNS precursor cells. J. Neurosci. 19, 8954-8965.

Ruiz I Altaba, A., Sanchez, P., and Dahmane, N. (2002). Gli and hedgehog in cancer: tumours, embryos and stem cells. Nat. Rev. Cancer 2, 361-372. doi: $10.1038 /$ nrc796

Schell-Apacik, C., Rivero, M., Knepper, J. L., Roessler, E., Muenke, M., and Ming, J. E. (2003). SONIC HEDGEHOG mutations causing human 
holoprosencephaly impair neural patterning activity. Hum. Genet. 113, 170-177. doi: 10.1007/s00439-003-0950-4

Tekki-Kessaris, N., Woodruff, R., Hall, A. C., Gaffield, W., Kimura, S., Stiles, C. D., et al. (2001). Hedgehog-dependent oligodendrocyte lineage specification in the telencephalon. Development 128, 2545-2554.

Ulfig, N., Briese, M., and Bohl, J. (2002). Expression of oligodendrocyte-specific protein (OSP)/claudin-11 in the human fetal forebrain. Neuroembriology 1 , 48-53. doi: 10.1159/000054263

Vallstedt, A., Klos, J. M., and Ericson, J. (2005). Multiple dorsoventral origins of oligodendrocyte generation in the spinal cord and hindbrain. Neuron 45, 55-67. doi: 10.1016/j.neuron.2004.12.026

Wilson, H. C., Onischke, C., and Raine, C. S. (2003). Human oligodendrocyte precursor cells in vitro: phenotypic analysis and differential response to growth factors. Glia 44, 153-165. doi: 10.1002/glia. 10280

Xu, Q., Guo, L., Moore, H., Waclaw, R. R., Campbell, K., and Anderson, S. A. (2010). Sonic hedgehog signaling confers ventral telencephalic progenitors with distinct cortical interneuron fates. Neuron 65, 328-340. doi: 10.1016/j.neuron.2010.01.004

Zecevic, N., Chen, Y., and Filipovic, R. (2005). Contributions of cortical subventricular zone to the development of the human cerebral cortex. J. Comp. Neurol. 491, 109-122. doi: 10.1002/cne.20714

Zhang, S.-C., Ge, B., and Duncan, I. D. (2000). Tracing human oligodendroglial development in vitro. J. Neurosci. Res. 59, 421-429. doi: 10.1002/(SICI)10974547(20000201)59:3<421::AID-JNR17>3.3.CO;2-3
Zhou, Q., and Anderson, D. J. (2002). The bHLH transcription factors OLIG2 and OLIG1 couple neuronal and glial subtype specification. Cell 109, 61-73. doi: 10.1016/S0092-8674(02)00677-3

Zhou, Q., Wang, S., and Anderson, D. J. (2000). Identification of a novel family of oligodendrocyte lineage-specific basic helix-loop-helix transcription factors. Neuron 25, 331-343. doi: 10.1016/S0896-6273(00)80898-3

Ziegler, E. C., and Ghosh, S. (2005). Regulating inducible transcription through controlled localization. Sci STKE 2005, re6. doi: 10.1126/stke.2842005re6

Conflict of Interest Statement: The authors declare that the research was conducted in the absence of any commercial or financial relationships that could be construed as a potential conflict of interest.

Received: 12 July 2013; accepted: 25 November 2013; published online: 13 December 2013.

Citation: Ortega JA, Radonjić NV and Zecevic N (2013) Sonic hedgehog promotes generation and maintenance of human forebrain Olig2 progenitors. Front. Cell. Neurosci. 7:254. doi: 10.3389/fncel.2013.00254

This article was submitted to the journal Frontiers in Cellular Neuroscience.

Copyright (c) 2013 Ortega, Radonjic and Zecevic. This is an open-access article distributed under the terms of the Creative Commons Attribution License (CC BY). The use, distribution or reproduction in other forums is permitted, provided the original author(s) or licensor are credited and that the original publication in this journal is cited, in accordance with accepted academic practice. No use, distribution or reproduction is permitted which does not comply with these terms. 